\title{
THE DIFFUSION OF RESEARCH ON THE ADOPTION AND DIFFUSION OF INFORMATION TECHNOLOGY
}

\author{
Yogesh K. Dwivedi \\ Michael D. Williams \\ Swansea University \\ Swansea, UK \\ Banita Lal \\ Nottingham Trent University \\ Nottingham, UK
}

\begin{abstract}
The considerable level of investigation into information systems and technology acceptance and diffusion to date has witnessed the use of an extensive range of exploratory techniques examining numerous diverse systems and technologies in a myriad of different contexts. The aim of this paper is to provide a comprehensive and systematic review of the literature relating to such adoption and diffusion issues in order to establish the current "state of play" in the domain along a number of dimensions including unit of analysis, research paradigm employed, technology examined, and theoretical models and constructs. Our findings suggest that the positivist paradigm, empirical and quantitative research, the survey method, and TAM theory were used predominantly when investigating the topics of adoption and diffusion of technology. Although the adoption of broad range of technologies has been examined, our results indicate that a number of technologies have so far received relatively little investigative attention.
\end{abstract}

Keywords Adoption, acceptance, diffusion, information systems, IT, ICT, research context, research issues, research method, theories

Please use the following format when citing this chapter:

Dwivedi, Y. K., Williams, M. D., and Lal, B., 2008, in IFIP International Federation for Information Processing, Volume 287, Open IT-Based Innovation: Moving Towards Cooperative IT Transfer and Knowledge Diffusion, eds. León, G., Bernardos, A., Casar, J., Kautz, K., and DeGross, J. (Boston: Springer), pp. 3-22. 


\section{INTRODUCTION}

The quest to ensure user-acceptance of information systems and technology (IS/IT) is an ongoing management challenge (Schwarz and Chin 2007), and one that has attracted the attention of the IS community to the extent that IS/IT adoption and diffusion research is considered to be among the more mature areas of exploration within the discipline (Hirschheim 2007; Venkatesh et al. 2007). This considerable level of investigation has witnessed the use of a wide range of exploratory techniques examining many different systems and technologies in countless different contexts, to the extent that even the most cursory examination of the extant literature will reveal a variety of stakeholder perspectives, technologies and contexts, units of analysis, theories, and research methods. For instance, contexts vary from the societal to the industrial, to the organizational and individual, and many theories and models — such as the technology acceptance model (TAM), diffusion of innovation (DoI) theory, theory of planned behavior (TPB), and institutional theory-have been utilized to study an assortment of adoption and diffusion related issues. Recently, researchers have begun extending their reach beyond the commonly addressed organization and user perspectives. For example, studies related specifically to the adoption of technology within the household context are beginning to emerge (Brown and Venkatesh 2005; Dwivedi et al. 2006; 2008a; Venkatesh and Brown 2001) adding yet further variability to the body of existing research in terms of contexts and units of analysis.

Reviewing and profiling the existing literature on IS/IT adoption and diffusion is likely to be of use to researchers in assisting them to identify currently under-explored themes, and to select theories and methods appropriate to their investigation, all of which are critical issues for conducting fruitful original and rigorous research. This will also help to identify existing strengths and weaknesses of pertinent research streams, promote discussion regarding critical issues in the area, and assist in the identification of alternative theoretical and methodological perspectives (Venkatesh et al. 2007).

qThere have been a number of reviews and meta-analytic articles published in the area to date. However, perhaps due to the customary inclination of researchers to make use of TAM, almost all existing studies have focused primarily upon reviewing the literature relating to technology acceptance rather providing a more comprehensive review on the broader area of adoption and diffusion. A number of these studies are discussed further in section 2. The general aim of this paper, therefore, is to provide a more comprehensive and systematic review of the literature pertaining to IS/IT adoption and diffusion research in order to ascertain the current "state of play" of the field along a number of dimensions. This overall aim is realized by means of the following objective: (1) to identify the journals publishing most articles on IS/IT adoption, acceptance, and diffusion; (2) to present the general trends on adoption and diffusion research according to the year of publication; (3) to identify countries (and hence areas of greatest activity) with the largest number of publications on IS/IT adoption, acceptance, and diffusion; (4) to identify authors active in the area of IS/IT adoption, acceptance, and diffusion; (5) to classify the publications according to three keywords, adoption, acceptance, and diffusion; (6) to identify the various units of analysis commonly utilized in IS/IT adoption, acceptance, and diffusion research; (7) to classify adoption and diffusion publications according to the research paradigm; (8) to classify adoption and diffusion publications on the basis of 
their use of primary research data (empirical and nonempirical); (9) to classify adoption and diffusion publications on the basis of the nature of the primary research data (quantitative and qualitative); (10) to classify adoption and diffusion publications according to the research methods employed; (11) to explore and identify the various technologies examined; (12) to explore the theories and theoretical constructs utilized when examining the adoption, acceptance, and diffusion of IS/IT within various contexts.

In order to realize these objectives, a systematic and comprehensive review of 883 articles appearing in 337 different peer-reviewed journals during the period 1970-2007 was conducted. The remainder of this paper is structured as follows. In section 2, we present a brief discussion of the existing literature reviewing adoption and diffusion research in the IS field. In section 3, we provide a discussion of the method we employed in our analysis of the trends of adoption and diffusion research. Our findings are presented and discussed in section 4 and, finally, section 5 presents our conclusions from this work and the limitations of our approach.

\section{LITERATURE REVIEW}

A number of review and meta-analysis articles have previously been published on the general theme of this paper (see Bagozzi 2007; Benbasat and Barki 2007; Choudrie and Dwivedi 2005a, 2005b; Dwivedi, Williams et al. 2008; Dwivedi, Williams, and Venkatesh 2008; Hirschheim 2007; Jeyaraj et al. 2006; King and He 2006; Legris et al. 2003; Lucas et al. 2007; Schwarz and Chin 2007; Silva 2007; Venkatesh et al. 2007). It should be noted that all but few of these studies (Choudrie and Dwivedi 2005b; Dwivedi, Williams et al. 2008; Dwivedi, Williams, and Venkatesh 2008; Jeyaraj et al. 2006) have adopted a rather narrow perspective of the area by focusing on reviewing and critiquing material that deals specifically with the issue of technology acceptance, particularly those works employing TAM or some aspect of it.

Choudrie and Dwivedi (2005b) considered the literature in general and examined the range of research methods used for studying technology adoption issues by reviewing 48 articles published in peer reviewed journals between 1985 and 2003. Despite attempting to extend the scope of such review articles, this study has two palpable limitations: first, its analysis was restricted to the research methodology employed, and second, its findings were based on a review of only 48 articles. The work of Jeyaraj et al. (2006) was based on a comparatively larger sample (99 articles), and provides a rigorous review of the predictors, linkages, and biases in IT innovation adoption research (thereby focusing on theoretical constructs), but again only gives consideration to publications appearing up until 2003.

To the best of our knowledge, there is no article that has yet provided a broad representation of the adoption, acceptance, and diffusion of IS/IT/innovation literature by systematically profiling a larger and more timely set of existing publications in terms of author, institution, country, publication year, research paradigm employed, nature of primary data, research methods, theories and theoretical constructs, and technology examined. It has been suggested by previous studies that such research is of importance in order to encourage debate about critical issues in the IS field (Hirschheim 2007) and to assist in the identification of alternative theoretical and methodological perspectives 
(Venkatesh et al. 2007). It is, therefore, suggested that the material presented in this paper will form a useful and incremental contribution to the existing knowledge of IS/IT/ICT/innovation adoption and diffusion

\section{RESEARCH METHODOLOGY}

The research presented in this paper employed a combination of bibliometric analysis, historical analysis (Chao et al. 2007) and meta-analysis (Avison et al. 2008; Palvia and Pinjani 2007) as a means of categorizing accumulated knowledge on adoption and diffusion of IS/IT/ICT. Chao et al. (2007) employed both bibliometric analysis and historical analysis in examining technology trends and forecasts of RFID, while a metaanalysis approach was adapted by three recently published studies profiling the theoretical and methodological underpinnings of articles published in the Information Systems Journal (Avison et al. 2008), Information \& Management (Palvia and Pinjani 2007), and Journal of Electronic Commerce Research (Dwivedi, Kiang et al. 2008). Given the overall aim of this paper, our approach employs a combination of these techniques.

For the purpose of conducting this research, we made use of the academic journals database provided by Thomson Scientific (previously known as the Institute for Scientific Information). Thomson Scientific publishes the Science Citation Index (SCI) and the Social Science Citation Index (SSCI) as two of three elements of its Web of Science ${ }^{\circledR}$ product. The reason for selecting this database is that the majority of IS journals are included either within the SCI or the SSCI. Therefore, it is possible to search for and locate a significant proportion of the published material on diffusion and adoption of IS/IT/ICT across various disciplines using the Web of Science ${ }^{\circledR}$ search facility. Moreover, restricting the search activities to a single publication database removed many of the potential problems of duplication inherent in the use of multiple data sources. The Web of Science ${ }^{\circledR}$ product provides two main search techniques: a general search and an advanced search. The search technique used within this research exercise was the general search. The main reason for employing a general search approach was simply that its easy to use characteristics facilitate the repetition of searches without any confusion, making it a straightforward process to obtain consistent results in repetitive searches provided the same search criteria are applied. This method of data collection was also adapted by a previous study on RFID (Chao et al. 2007).

In order to identify publications specific to the adoption and diffusion area, two sets of search terms were employed in this study. The first set of search criteria included three key words: DIFFUSION, ADOPTION, and ACCEPTANCE. The search was restricted to occurrences of any of these keywords appearing in the article title in order to avoid locating publications where keywords might have appeared generally within the main text. However, if one of these words appeared in the article title, it suggested that the focus of the article was adoption and diffusion in some form. A second set of search terms comprising keywords such as IT, INFORMATION TECHNOLOGY, IS, INFORMATION SYSTEM, INFORMATION SYSTEMS, ICT, INFORMATION AND COMMUNICATION TECHNOLOGY, INFORMATION AND COMMUNICATION TECHNOLOGIES, and INTERNET was also applied. In this case, the search was restricted to occurrences of any of the keywords appearing in the article topic/keywords 
list. Combining the two sets of search terms resulted in the extraction of 883 records providing details on publications relating to adoption, acceptance, or diffusion of IS/IT/ICT. All 883 items were then examined manually in order to cross-check and confirm the relevance of the search results.

A number of analyses were then conducted on the search output employing the various analysis tools available in the Web of Science ${ }^{\circledR}$. Count and percentage data was generated for the assorted variables utilized to categorize the search output. Variables analyzed included subject category, journal in which an article appeared, year of publication, author, author's institution, and the country in which the research was conducted. A further detailed manual analysis was then conducted in order to extract various items of information that could not be obtained directly from the Web of Science ${ }^{\circledR}$ database. In order to do so, we examined each of the abstracts of the articles contained in the search results. Then these abstracts were individually scrutinized in order to obtain and record information such as the unit or level of analysis, the research paradigm, issues pertaining to primary data, the form of technology examined, and so on. It is important to note that due to time constraints and the amount of effort required to conduct the analysis, some of the results presented in this paper arise from the analysis of a subset of 301 of the total 883 articles available for consideration. We are continuing to analyze the remaining 582 publications; the results of the entire analysis will be reported elsewhere when available.

Data obtained from this analysis relating to the variables under examination were first recoded in SPSS v.14, and then count and percentage values generated. With the exception of variables referring to the methodological approaches, data on all the other variables were recorded without considering the prespecified categories. For the methodological variables, we adopted categories from the previous studies of Avison et al. (2008), Choudrie and Dwivedi (2005b), Dwivedi, Kiang et al. (2008), Dwivedi, Williams, and Venkatesh (2008), Galliers (1992), and Galliers and Land (1987).

\section{FINDINGS}

\subsection{Adoption and Diffusion Studies According to Subject Category}

A total of $107 \mathrm{Web}$ of Science ${ }^{\circledR}$ subject categories have published research on adoption and diffusion of IS/IT/ICT. Table 1 illustrates the top 20 Web of Science ${ }^{\circledR}$ subject categories, the largest number of articles (292) appearing within the "Computer Science, Information Systems" category on adoption and diffusion of IS/IT/ICT. This is followed by the "Information Science \& Library Science" category (240), and then the "Management" category (237). The lowest count (16) presented in this table is for subject category "Planning \& Development." For remaining 87 categories, article count varies between 15 to 1 articles. The lowest number of articles in our study (1) appeared in the 35 different categories while 2 articles each appeared in 16 different categories preceded by 5 categories with only 3 articles each and 10 categories with 4 articles each. It is important to note at this point that these results are indicative only, and are intended to provide a representation of the main areas of study in which research articles on adoption and diffusion of information systems are likely to appear. Clearly, extending the number of keywords and altering the categories included would alter the results, 
Table 1. IS/IT/ICT Adoption and Diffusion Studies According to Subject Category

\begin{tabular}{|l|c|c|}
\hline \multicolumn{1}{|c|}{ Subject Category (N= 107) } & $\begin{array}{c}\text { Article Count } \\
(\mathbf{n = 8 8 3})\end{array}$ & $\begin{array}{c}\text { \% of } \\
\mathbf{8 8 3}\end{array}$ \\
\hline Computer Science, Information Systems & 292 & $33.07 \%$ \\
\hline Information Science \& Library Science & 240 & $27.18 \%$ \\
\hline Management & 237 & $26.84 \%$ \\
\hline Business & 92 & $10.42 \%$ \\
\hline Operations Research \& Management Science & 70 & $7.93 \%$ \\
\hline Computer Science, Interdisciplinary Applications & 65 & $7.36 \%$ \\
\hline Engineering, Industrial & 59 & $6.68 \%$ \\
\hline Economics & 46 & $5.21 \%$ \\
\hline Medical Informatics & 36 & $4.08 \%$ \\
\hline Computer Science, Theory \& Methods & 35 & $3.96 \%$ \\
\hline Telecommunications & 32 & $3.62 \%$ \\
\hline Health Care Sciences \& Services & 30 & $3.40 \%$ \\
\hline Communication & 29 & $3.28 \%$ \\
\hline Computer Science, Software Engineering & 25 & $2.83 \%$ \\
\hline Computer Science, Artificial Intelligence & 24 & $2.72 \%$ \\
\hline Ergonomics & 24 & $2.72 \%$ \\
\hline Psychology, Multidisciplinary & 21 & $2.38 \%$ \\
\hline Computer Science, Cybernetics & 16 & $2.27 \%$ \\
\hline Engineering, Electrical \& Electronic & 16 & $1.81 \%$ \\
\hline Planning \& Development & $1.81 \%$ \\
\hline
\end{tabular}

although, it is argued, not to the extent that it would substantially alter the overall profile. ${ }^{1}$

Table 2 presents the breakdown of our search output according to the journals in which the articles on adoption and diffusion of IS/IT/ICT appeared. A total of 337 outlets have published 883 articles on adoption and diffusion of IS/IT/ICT. Table 2 illustrates the top 20 source titles, suggesting that the largest number of articles (60) on adoption and diffusion appeared in the journal Information \& Management and the least number of articles (1) resulting from our search activities appeared in 223 source titles. Other journals that have published a significant number of articles on adoption and diffusion include European Journal of Information Systems (26), IEEE Transactions on Engineering Management (23), Journal of the American Medical Informatics Association (19), MIS Quarterly (19), Information Systems Research (17), and Journal of Computer Information Systems (17). Our findings further reveal that of the journals publishing the highest numbers of articles on adoption and diffusion of IS/IT/innovation, only few (European Journal of Information Systems and Journal of Information Technology) are based in Europe, all the others being based in North America. This could be due to the fact that a large number of the articles in our search results were quantitative in nature, and it could well be the case that U.S.-based journals are comparatively more sympathetic to such material (Lyytinen et al. 2007; Palvia and Pinjani 2006). The list also suggests

${ }^{1}$ Due to space limitations, not all subject categories are listed here. The categories and other information relating to the development of this paper are available from the authors. 
Table 2. IS/IT/ICT Adoption and Diffusion Studies According to Journal

\begin{tabular}{|l|c|c|}
\hline \multicolumn{1}{|c|}{ Journal Title } & $\begin{array}{c}\text { Article Count } \\
(\mathbf{n = 8 8 3})\end{array}$ & $\begin{array}{c}\mathbf{\%} \text { of } \\
\mathbf{8 8 3}\end{array}$ \\
\hline Information \& Management & 60 & $6.80 \%$ \\
\hline European Journal of Information Systems & 26 & $2.94 \%$ \\
\hline IEEE Transactions on Engineering Management & 23 & $2.60 \%$ \\
\hline Journal of the American Medical Informatics Association & 19 & $2.15 \%$ \\
\hline MIS Quarterly & 19 & $2.15 \%$ \\
\hline Information Systems Research & 17 & $1.93 \%$ \\
\hline Journal of Computer Information Systems & 17 & $1.93 \%$ \\
\hline Decision Support Systems & 16 & $1.81 \%$ \\
\hline International Journal of Information Management & 14 & $1.59 \%$ \\
\hline Journal of Information Technology & 14 & $1.59 \%$ \\
\hline Industrial Management \& Data Systems & 13 & $1.47 \%$ \\
\hline Journal of Management Information Systems & 13 & $1.47 \%$ \\
\hline Technovation & 11 & $1.25 \%$ \\
\hline Telecommunications Policy & 11 & $1.25 \%$ \\
\hline Communications of the ACM & 10 & $1.13 \%$ \\
\hline Decision Sciences & 10 & $1.13 \%$ \\
\hline International Journal of Human-Computer Studies & 10 & $1.13 \%$ \\
\hline International Journal of Medical Informatics & 9 & $1.02 \%$ \\
\hline Internet Research-Electronic Networking Applications and & 9 & $1.02 \%$ \\
\hline Policy & 9 & $1.02 \%$ \\
\hline Journal of Business Research & &
\end{tabular}

that although the majority of journals are from the Information Systems discipline, a number of journals from other disciplines (Journal of the American Medical Informatics Association, Telecommunication Policy, International Journal of Medical Informatics, and Journal of Business Research) have also published IS/IT/ICT adoption and diffusion research. This clearly shows the cross-disciplinary nature of IS/IT adoption and diffusion research. $^{2}$

\subsection{Adoption and Diffusion Studies According to Year of Publication}

Our findings (illustrated in Table 3) reveal that the number of articles published on adoption and diffusion has constantly increased from 1989 (when three papers were published in various journals) to 2007 (which has so far seen 123 papers appear). To date, the largest number of articles (142) appeared in 2006, closely followed by 2005 and 2007, each with a count of 123 articles. Prior to 1989, a low number of articles appeared in each year, with no articles at all appearing in our selected journals during some years.

${ }^{2}$ Due to space limitations, not all source titles are listed here. A complete list is available from the authors. 
Table 3. Adoption and Diffusion Studies Published from 1970 through 2007

\begin{tabular}{|c|c|c|c|c|c|c|c|c|}
\hline Year & $\begin{array}{c}\text { Article } \\
\text { Count } \\
(\mathbf{n = 8 8 3})\end{array}$ & $\begin{array}{c}\text { \% of } \\
\mathbf{8 8 3}\end{array}$ & Year & $\begin{array}{c}\text { Article } \\
\text { Count } \\
(\mathbf{n = 8 8 3})\end{array}$ & $\begin{array}{c}\text { \% of } \\
\mathbf{8 8 3}\end{array}$ & $\begin{array}{c}\text { Article } \\
\text { Count } \\
(\mathbf{n = 8 8 3})\end{array}$ & $\begin{array}{c}\text { Yo of } \\
\mathbf{8 8 3}\end{array}$ \\
\hline 2006 & 142 & $16.08 \%$ & 1997 & 35 & $3.96 \%$ & 1990 & 5 & $0.57 \%$ \\
\hline 2005 & 123 & $13.93 \%$ & 1999 & 27 & $3.06 \%$ & 1989 & 3 & $0.34 \%$ \\
\hline 2007 & 123 & $13.93 \%$ & 1994 & 19 & $2.15 \%$ & 1980 & 2 & $0.23 \%$ \\
\hline 2003 & 85 & $9.63 \%$ & 1995 & 13 & $1.47 \%$ & 1985 & 2 & $0.23 \%$ \\
\hline 2004 & 66 & $7.47 \%$ & 1992 & 12 & $1.36 \%$ & 1987 & 2 & $0.23 \%$ \\
\hline 2002 & 60 & $6.80 \%$ & 2008 & 11 & $1.25 \%$ & 1970 & 1 & $0.11 \%$ \\
\hline 2001 & 47 & $5.32 \%$ & 1993 & 10 & $1.13 \%$ & 1978 & 1 & $0.11 \%$ \\
\hline 1998 & 38 & $4.30 \%$ & 1996 & 10 & $1.13 \%$ & 1981 & 1 & $0.11 \%$ \\
\hline 2000 & 38 & $4.30 \%$ & 1991 & 6 & $0.68 \%$ & 1984 & 1 & $0.11 \%$ \\
\hline
\end{tabular}

While it may be argued that the increasing number of articles appearing post-1989 illustrates increasing levels of interest and research activity in the subject area, the lack of articles prior to this time may be attributed to a number of reasons, including that not all of the journals in our search list were published in each year. This point is particularly applicable to the earlier years considered.

\subsection{Adoption and Diffusion Studies According to Country}

Our findings (illustrated in Table 4) disclose that the research presented in the 883 publications we identified on adoption and diffusion was conducted in 52 countries. By

Table 4. IS/IT/ICT Adoption and Diffusion Studies According to Country

\begin{tabular}{|l|c|l|c|l|c|}
\hline \multicolumn{1}{|c|}{ Country } & $\begin{array}{c}\text { AC } \\
(\mathbf{n = 8 8 3 )}\end{array}$ & \multicolumn{1}{c|}{ Country } & $\begin{array}{c}\text { AC } \\
(\mathbf{n = 8 8 3})\end{array}$ & \multicolumn{1}{c|}{ Country } & $\begin{array}{c}\text { AC } \\
(\mathbf{n = 8 8 3})\end{array}$ \\
\hline USA & 463 & India & 8 & South Africa & 2 \\
\hline UK & 78 & New Zealand & 8 & Turkey & 2 \\
\hline Peoples R China & 50 & Austria & 6 & Botswana & 1 \\
\hline Canada & 47 & Brazil & 6 & Dominican Rep & 1 \\
\hline Taiwan & 44 & Japan & 6 & Egypt & 1 \\
\hline Australia & 39 & Sweden & 6 & Ethiopia & 1 \\
\hline South Korea & 33 & Switzerland & 6 & Indonesia & 1 \\
\hline Germany & 29 & Belgium & 5 & Malawi & 1 \\
\hline Netherlands & 26 & Hong Kong & 5 & Mexico & 1 \\
\hline Singapore & 26 & Portugal & 5 & Philippines & 1 \\
\hline Spain & 18 & U Arab Emirates & 5 & Poland & 1 \\
\hline Italy & 17 & Ireland & 4 & Slovakia & 1 \\
\hline France & 13 & Saudi Arabia & 4 & Slovenia & 1 \\
\hline Finland & 12 & Fed Rep Ger & 3 & Thailand & 1 \\
\hline Denmark & 11 & Kenya & 3 & Uruguay & 1 \\
\hline Greece & 9 & Malaysia & 3 & Vietnam & 1 \\
\hline Israel & 9 & Nigeria & 3 & & \\
\hline Norway & 9 & Ghana & 2 & & \\
\hline
\end{tabular}


far the largest amount of published activity has taken place in the United States, with a number of others countries (including the United Kingdom, China, Canada, Taiwan, Australia, South Korea, Germany, the Netherlands, and Singapore) also being the location of a substantial amount of research activity resulting in publications that appeared in our search results.

A number of countries (including Finland, France, India, Ireland, Malaysia, and the Philippines) have been the location of research resulting in a low number of publications, and, given the overall level of research activity in such countries, and indeed the supposed high-profile of ICT, this is perhaps a surprising result and indicates that there is opportunity for additional research based in such counties to take place in order to further expand the existing knowledge base.

\subsection{Authors Actively Involved in Publishing Adoption and Diffusion Research}

A total of 1,767 authors contributed to the 883 articles on adoption and diffusion of IS/IT/ICT. Table 5 lists the authors most actively involved in conducting and publishing adoption and diffusion related research. It appears that the most productive author in adoption and diffusion research (in terms of journal publications across the journals in our search) is Venkatesh, V with 15 articles, followed by Chau, PYK, with 10 articles. Thereafter three authors (Davis, FD; Morris, MG, and Tam, KY) contributed eight articles each, two authors (Kraemer, KL and Zhu, K) contributed seven articles each, four authors contributed six articles each and five authors contributed five articles each (see Table 5 for names). This is followed by 13 authors with 4 articles each and 45 authors contributed 3 articles each.

From the list of 1,767 authors, 132 contributed 2 articles each, while a vast majority of authors (1,561 authors) contributed to just 1 article in the set of journals comprising our search data. ${ }^{3}$

\subsection{Adoption and Diffusion Studies According to Institution}

A total of 732 institutions are represented by authors contributing to the 883 articles on adoption and diffusion of IS/IT/ICT. Table 6 identifies the institutions apparently most active in the area of adoption and diffusion research. The overall number of contributions from each university varies from 1 to 19 . Clearly the National University of Singapore (with 19 publications) has contributed the largest number and can, therefore, be seen a leading center of adoption and diffusion related research. This is closely followed by the University of Maryland (with 18 publications). A number of other institutions also have been the source of a noteworthy number of publications over the years, including the Georgia State University and the Hong Kong University of Science and Technology, each with 16 publications; Florida State University, University of Cali-

${ }^{3}$ Due to space limitations, not all authors are listed here. A complete list is available from the authors. 
Table 5. Authors Actively Involved in Publishing IS/IT/ICT Adoption and Diffusion Research

\begin{tabular}{|l|c|l|c|l|c|}
\hline \multicolumn{1}{|c|}{ Author } & AC & \multicolumn{1}{c|}{ Author } & AC & \multicolumn{1}{c|}{ Author } & AC \\
\hline Venkatesh, V & 15 & Prasad, J & 4 & Kim, M & 3 \\
\hline Chau, PYK & 10 & Ramamurthy, K & 4 & Lee, SM & 3 \\
\hline Davis, FD & 8 & Riemenschneider, CK & 4 & Lewis, LF & 3 \\
\hline Morris, MG & 8 & Thong, JYL & 4 & Lin, CA & 3 \\
\hline Tam, KY & 8 & Benbasat, I & 3 & Lou, H & 3 \\
\hline Kraemer, KL & 7 & Chang, IC & 3 & Lyytinen, K & 3 \\
\hline Zhu, K & 7 & Cheng, TCE & 3 & Mbarika, VWA & 3 \\
\hline Agarwal, R & 6 & Cheung, CMK & 3 & Molla, A & 3 \\
\hline Hu, PJH & 6 & Choudrie, J & 3 & Nault, BR & 3 \\
\hline Premkumar, G & 6 & Chukmaitov, A & 3 & Pervan, G & 3 \\
\hline Teo, TSH & 6 & Damsgaard, J & 3 & Pries-Heje, J & 3 \\
\hline Brooks, RG & 5 & Dexter, AS & 3 & Quaddus, M & 3 \\
\hline Igbaria, M & 5 & Dinlersoz, EM & 3 & Rai, A & 3 \\
\hline Lai, VS & 5 & Dwivedi, YK & 3 & Ravichandran, T & 3 \\
\hline Lee, MKO & 5 & Farn, CK & 3 & Saunders, C & 3 \\
\hline Menachemi, N & 5 & Forman, C & 3 & Shih, HP & 3 \\
\hline Bajwa, DS & 4 & Foster, W & 3 & Straub, DW & 3 \\
\hline Bhattacherjee, A & 4 & Gefen, D & 3 & Wang, YS & 3 \\
\hline Brown, SA & 4 & Goldfarb, A & 3 & Watanabe, C & 3 \\
\hline Fichman, RG & 4 & Hardgrave, BC & 3 & Wu, JH & 3 \\
\hline Grover, V & 4 & Hong, SJ & 3 & Xu, S & 3 \\
\hline Hwang, HG & 4 & Hong, WY & 3 & Xu, SX & 3 \\
\hline Lee, J & 4 & Karahanna, E & 3 & Yang, H & 3 \\
\hline Ngai, EWT & 4 & Kauffman, RJ & 3 & Yu, CS & 3 \\
\hline Pavlou, PA & 4 & Kemerer, CF & 3 & & \\
\hline
\end{tabular}

fornia-Irvine, and the University of Wisconsin contributed to 14 publications each. Table 6 illustrates that six universities contributed 12 articles each, followed by the University of Arizona with 11 contributions and seven universities each contributing 10 articles. A further five universities contributed nine articles each, while Harvard and the University of Pennsylvania were the source of eight articles each. These and the remaining institutions are identified in Table 6. A further 116 universities (not listed) contributed two articles each, while 488 universities were the source of just one article. ${ }^{4}$

The largest amount of research activity resulting in journal publications has occurred at universities in the United States, and, to an extent, at institutions based in Singapore and Hong Kong. It is interesting to note that only four European universities appear in our list (Athens University of Economics \& Business, Bocconi University, Brunel University, and Free University of Amsterdam), which includes only one university from the United Kingdom. The list also includes two Australian universities (Curtin Unive-

${ }^{4}$ Due to space limitations, not all institutions producing fewer than five articles over the period under study are listed here. The complete list is available from the authors. 
Table 6. Universities Facilitating IS/IT/ICT Adoption and Diffusion Research Resulting in Journal Publications

\begin{tabular}{|c|c|c|c|c|c|}
\hline University & $\overline{A C}$ & University & $\overline{\mathrm{AC}}$ & University & $\overline{\mathrm{AC}}$ \\
\hline Natl Univ Singapore & 19 & Iowa State Univ & 9 & Texas Tech Univ & 6 \\
\hline Univ Maryland & 18 & Natl Chung Cheng Univ & 9 & Univ Colorado & 6 \\
\hline Georgia State Univ & 16 & Univ So Calif & 9 & Univ Dayton & 6 \\
\hline $\begin{array}{l}\text { Hong Kong Univ Sci \& } \\
\text { Technol }\end{array}$ & 16 & Univ Utah & 9 & Univ Georgia & 6 \\
\hline Florida State Univ & 14 & Harvard Univ & 8 & Univ Missouri & 6 \\
\hline Univ Calif Irvine & 14 & Univ Penn & 8 & Univ New S Wales & 6 \\
\hline Univ Wisconsin & 14 & Brunel Univ & 7 & Univ S Carolina & 6 \\
\hline Michigan State Univ & 12 & $\begin{array}{l}\text { Chinese Univ Hong } \\
\text { Kong }\end{array}$ & 7 & Univ Western Ontario & 6 \\
\hline Univ Arkansas & 12 & Curtin Univ Technol & 7 & Yonsei Univ & 6 \\
\hline Univ Houston & 12 & $\begin{array}{l}\text { George Washington } \\
\text { Univ }\end{array}$ & 7 & Arizona State Univ & 5 \\
\hline Univ Minnesota & 12 & Natl Sun Yat Sen Univ & 7 & $\begin{array}{l}\text { Athens Univ Econ \& } \\
\text { Business }\end{array}$ & 5 \\
\hline Univ N Carolina & 12 & Ohio State Univ & 7 & Bocconi Univ & 5 \\
\hline Univ Texas & 12 & So Illinois Univ & 7 & Boston Univ & 5 \\
\hline Univ Arizona & 11 & Stanford Univ & 7 & Duke Univ & 5 \\
\hline Carnegie Mellon Univ & 10 & Syracuse Univ & 7 & Free Univ Amsterdam & 5 \\
\hline City Univ Hong Kong & 10 & Univ Illinois & 7 & Louisiana State Univ & 5 \\
\hline $\begin{array}{l}\text { Hong Kong Polytech } \\
\text { Univ }\end{array}$ & 10 & Univ Michigan & 7 & Miami Univ & 5 \\
\hline Indiana Univ & 10 & Univ Virginia & 7 & Nyu & 5 \\
\hline Univ British Columbia & 10 & Washington State Univ & 7 & $\begin{array}{l}\text { United Arab Emirates } \\
\text { Univ }\end{array}$ & 5 \\
\hline Univ Hong Kong & 10 & Clemson Univ & 6 & Univ Alabama & 5 \\
\hline Univ S Florida & 10 & Natl Cent Univ & 6 & Univ Pittsburgh & 5 \\
\hline Drexel Univ & 9 & Rutgers State Univ & 6 & & \\
\hline
\end{tabular}

sity of Technology and the University of New South Wales). However, the list is overall largely dominated by additional U.S.-based institutions. Our results, therefore, provide a strong indication that adoption and diffusion research resulting in journal publications takes place primarily in the United States, Singapore, and Hong Kong, with comparatively lower levels of activity (to date) taking place elsewhere.

\subsection{Language of Publications}

Our findings disclose that the research presented in the 883 publications we identified on adoption and diffusion was communicated in seven languages. By far the largest amount of articles were communicated in English (869), with a very few numbers of articles published in German (9), Finnish (1), French (1), Russian (1), Slovak (1), and Spanish (1). 
Table 7. Use of Adoption, Acceptance, or Diffusion in Article Title

\begin{tabular}{|l|c|c|}
\hline \multicolumn{1}{|c|}{ Keyword } & Count (n=301) & Percent \\
\hline Adoption & 178 & 59.1 \\
\hline Acceptance & 81 & 26.9 \\
\hline Diffusion & 42 & 14.0 \\
\hline
\end{tabular}

\subsection{Document Type}

The findings suggest that the research presented in the 883 publications we identified on adoption and diffusion were largely research articles (806), followed by 42 review articles and 15 editorials. Very few articles were classified as a book review (7), meeting abstract (5), news item (4), letter (2), or note (2).

\subsection{Adoption, Acceptance or Diffusion?}

Although the findings presented thus far include the total 345 articles identified from our search activities, hereafter only 301 articles provide the basis for the basis for profiling adoption and diffusion research output. At this stage, all articles from Communications of the ACM and a number of articles from other outlets were necessarily eliminated due to the non-availability of abstracts for analysis. The primary reason for excluding the Communications of the ACM articles from the analysis is that the format and content of articles as published differ from other IS journals, and hence, it is often difficult to extract methodological and theoretical information from them. Three keywords, ADOPTION, ACCEPTANCE, and DIFFUSION, were employed to search published output for this study. Table 7 presents information on the number of occurrences of each term in our search results. It can be seen from Table 7 that the keyword ADOPTION was used by the largest number of articles (178) followed by ACCEPTANCE (81), with the term DIFFUSION being employed by the least number of items appearing in our search results (42).

\subsection{Adoption and Diffusion Studies According to Unit/Level of Analysis}

The results of our exploration into the most common forms of unit of analysis employed are presented in Table 8. It can be seen that the majority of articles (105) appearing in our search results examined adoption and diffusion issues at the organizational level, closely followed by studies focusing on user adoption and acceptance of IS/IT (92). Far fewer articles were found to examine adoption and diffusion in the context of Groups/ Teams (2) and the household (3). 
Table 8. Unit of Analysis

\begin{tabular}{|l|c|c|l|c|c|}
\hline Unit of Analysis & $\begin{array}{c}\text { Count } \\
(\mathbf{n = 3 0 1})\end{array}$ & $\mathbf{\%}$ & Unit of Analysis & $\begin{array}{c}\text { Count } \\
(\mathbf{n = 3 0 1})\end{array}$ & $\mathbf{\%}$ \\
\hline Organization/Firm & 105 & 34.9 & Industry & 4 & 1.3 \\
\hline User & 92 & 30.6 & Stakeholders & 3 & 1.0 \\
\hline Consumer & 42 & 14.0 & Household & 3 & 1.0 \\
\hline SME & 26 & 8.6 & Other & 3 & 1.0 \\
\hline Subject/Theory/Tool/System & 20 & 6.9 & Group/Team & 2 & 0.7 \\
\hline Country & 7 & 2.3 & & & \\
\hline
\end{tabular}

\subsection{Adoption and Diffusion Studies According to Research Paradigm}

The findings clearly indicates that positivism (used in 225 articles, 74.8 percent) is the dominant or most popular research paradigm among adoption and diffusion researchers, followed some way behind by the interpretive paradigm (being employed in 42 articles, 14.0 percent). We have labeled the third category "Descriptive/Conceptual/ Theoretical" (being employed in 27 articles, 9.0 percent) and it includes papers that do not neatly fit into either positivist or interpretive categories, primarily comprising articles based on literature reviews, personal view points, or studies that are highly conceptual in nature (Avison et al. 2008). For seven articles (2.3 percent), the paradigm was unclear and hence it was not apparent if they should be placed in either the positivist or interpretive category.

\subsection{Research Methodology: Empirical Versus Nonempirical}

A very large proportion of articles within our search results (273 articles, 90.7 percent ) were empirical in nature in comparison to articles that fell within the nonempirical category (23 articles, 7.6 percent). However, for five articles (1.7 percent), it was not possible to determine if they were empirical or nonempirical in nature, due to the lack of relevant information.

\subsection{Research Methodology: Quantitative Versus Qualitative}

The findings suggest that the quantitative approach has dominated adoption and diffusion research within the IS discipline. A total of 195 articles (64.8 percent) employed a quantitative approach (which also includes descriptive quantitative articles) in comparison to the qualitative approach which was employed by only 68 articles (22.6 percent) and conceptual approach at third place with 26 articles (8.6 percent). Four articles (1.3 percent) employed a mix of data types, while for eight articles (2.7 percent) it was not possible to determine the primary approach employed. 
Table 9. Research Methods (Categories are adapted from Avison et al. 2998; Dwivedi, Williams et al. 2008; Dwivedi, Williams, and Venkatesh 2008)

\begin{tabular}{|l|c|c|l|c|c|}
\hline \multicolumn{1}{|c|}{ Research Method } & $\begin{array}{c}\text { Count } \\
(\mathbf{n = 3 0 1 )}\end{array}$ & $\mathbf{\%}$ & \multicolumn{1}{|c|}{ Research Method } & $\begin{array}{c}\text { Count } \\
(\mathbf{n = 3 0 1})\end{array}$ & $\mathbf{\%}$ \\
\hline Survey & 173 & 57.5 & Laboratory experiment & 3 & 1.0 \\
\hline Case Study & 46 & 15.3 & Secondary Data Analysis & 3 & 1.0 \\
\hline $\begin{array}{l}\text { Literature analysis/ } \\
\text { Conceptual/Meta-analysis }\end{array}$ & 29 & 9.6 & Field experiment & 2 & .7 \\
\hline Field Study & 11 & 3.7 & Content Analysis & 2 & .7 \\
\hline Interview & 7 & 2.3 & Action research & 1 & .3 \\
\hline Mathematical model & 6 & 2.0 & Not Known & 12 & 4.0 \\
\hline Multi-method & 6 & 2.0 & & & \\
\hline
\end{tabular}

\subsection{Research Methods}

Table 9 illustrates that although a total of 12 different research methods were recorded from our data analysis activities, the majority of studies (173) in our results employed survey methods. The other major category employed was case study, which was used in 46 articles. Other approaches identified include literature review/conceptual/ meta-analysis (29), field study (11), and interview (7). All remaining categories were employed by very few studies, with only one article employing action research.

\subsection{The Technology Examined}

Table 10 lists the diverse range of technologies examined in the 301 publications that formed our search results. It is clear from Table 10 that the scope is broad and, to an extent, reflects the emergence of different technologies over the period under consideration. In order to organize the technologies effectively, we have grouped them in the following broad categories: communication, electronic commerce, information systems, information technologies, Internet, mobile, and website. In Table 10, the figures in parentheses indicate the number of articles in each case, and it can be seen that the IS category has been most widely studied, followed by electronic commerce related issues. The least studied broad area to date appears to be that of mobile technology, although Table 10 reveals a range of specific technologies, applications, and contexts that appear to have received little investigative attention.

\subsection{Theories/Models and Theoretical Constructs}

Table 11 illustrates the diversity of theories employed in the study of adoption and diffusion concepts in relation to information systems. TAM has emerged as the most popular theory with 88 studies (29 percent) employing it, followed by DoI theory, which was used in 49 publications (16.3 percent). The third largest category was TPB, which 
Table 10. Technologies Examined

\begin{tabular}{|c|c|}
\hline Category & Technology/System \\
\hline $\begin{array}{l}\text { Communication } \\
(15)\end{array}$ & $\begin{array}{l}\text { Communication Standards (1); Email (9); Fax (1); Instant Messaging/ } \\
\text { Wireless SMS (3); High Speed Data Services (1) }\end{array}$ \\
\hline $\begin{array}{l}\text { Electronic } \\
\text { Applications \& } \\
\text { Technologies (74) }\end{array}$ & $\begin{array}{l}\text { B2B Exchanges (1); B2B Marketplaces (1); B2B Portals (1); B2B, P2P } \\
\text { and e-Speak (1); C2C Auction System/Online Escrow Services (1); E- } \\
\text { banking/Internet Banking/Electronic Billing/Virtual Banking (7); E- } \\
\text { Business/E-Business Technologies (7); E-Commerce/E-Shopping/E- } \\
\text { Commerce Technologies (25); E-Marketplace (2); Electronic Service } \\
\text { (1); Electronic Tax Filing (1); Electronic Trading (3); Price Compari- } \\
\text { son Shopping (1); EDI (9); E-Learning System and technology (2); E- } \\
\text { Government/E-Gov Services/E-Voting (5); Electronic Health Records } \\
\text { (EHRs)/Electronic Patient Record (EPR) (2); Application Service } \\
\text { Oriented Medical Records (1); E-Sales, C-Procurement (1); Products in } \\
\text { Electronic Markets (1); Proprietary and Open Systems (1) }\end{array}$ \\
\hline $\begin{array}{l}\text { Information } \\
\text { Systems/Systems/ } \\
\text { IS Development/ } \\
\text { IS Management } \\
(80)\end{array}$ & $\begin{array}{l}\text { Agile Adoption Practices (1); Application Service Provision (ASP) (1); } \\
\text { BPR (2); B2B Eprocurement System (1); Business to Business } \\
\text { Ordering System (1); CASE (8); Client Server Systems (1); Computer- } \\
\text { based Information Systems (1); CRM (2); Design Methodologies of } \\
\text { Component Based Architecture (1); Document Management System } \\
\text { (1); DSS\&TPS (1); End-user Computing (1); Enterprise Application } \\
\text { Integration (EAI) (1); Enterprise Digital Transformation (1); Enterprise } \\
\text { Level Systems (1); Enterprise Resource Planning (ERP) (8); Expert } \\
\text { Systems and Expert Systems in Banking Industry (5); Expert Systems } \\
\text { Advice (1); Group Support Systems (GSS) (2); Groupware (1); Lotus } \\
\text { Notes (1); Healthcare Information Systems and Healthcare Information } \\
\text { Technology (HIT) (3); Information Systems (6); Sales Information } \\
\text { Systems (1); Hedonic Information Systems (1); Securities Trading } \\
\text { Systems (1); IOS (2); IS Development Methods (ISDMs) (1); IS Pro- } \\
\text { cess Innovation (1); EIS (4); Knowledge (1); Office Suite Applications } \\
\text { - Spreadsheet, Database, Word, Graphics (2); Open Systems (2); } \\
\text { Recommendation Agent (1); Outsourcing (3); Systems (2); System } \\
\text { Development Methodology (1); System/Technology Use (1); User } \\
\text { Involvement (1); Volitional/Voluntary Systems (1); Software System } \\
\text { (1); Electronic Brain Storming (1); Software Development Tool (1); } \\
\text { Software Re-use (2); Virtual Community Service - Avatar (1); Visual } \\
\text { Information (1); Telecommuting (2) }\end{array}$ \\
\hline $\begin{array}{l}\text { Information } \\
\text { Technology/ICT/ } \\
\text { Technology/Soft- } \\
\text { ware (70) }\end{array}$ & $\begin{array}{l}\text { Advanced Manufacturing Technology (1); Broadband and Broadband } \\
\text { Mobile Services (7); Collaborative Information Technology (1); Data } \\
\text { warehouse (3); DBMS \& Distributed DBMS (3); Digital Library (1); } \\
\text { Family Technology Resource Center (1); IT (17); IT in Education (1); } \\
\text { IT Innovation (2); Mandated IT (1); IT Platform (1); ICT (3); Personal } \\
\text { Computer (PC)/Personal Computing (6); Tablet PC (1); Radio } \\
\text { Frequency Identification (RFID) (1); Public Grid Computing (1); Self- } \\
\text { Service Technology (1); Commercial Software Packages (1); Windows } \\
\text { technology (1); Smart Card-based Payment Systems/micro payment } \\
\text { infrastructure (2); Telemedicine Technology (4); Videotex newspaper } \\
\text { (1); Knowledge Management Technologies (1); Object-oriented } \\
\text { Technologies/Object technology (2); Tech. Mediated Distance } \\
\text { Education (TMDE) (1); Technological Innovations (1); Technology } \\
\text { (2); ATM (2) }\end{array}$ \\
\hline
\end{tabular}




\begin{tabular}{|c|c|}
\hline Category & Technology/System \\
\hline $\begin{array}{l}\text { Internet/Online } \\
(26)\end{array}$ & $\begin{array}{l}\text { Internet (11); Internet-based product customisation (1); Internet Based } \\
\text { Learning Medium (ILM) (1); Internet Retailing (1); ISPs (1); Internet } \\
\text { Standards - IPv6 (1); Intranet (1); ISDN-Integrated Services Digital } \\
\text { Network (1); National Infrastructure (1); On-line Learning Systems (1); } \\
\text { Online Consumer Behaviour (1); Online Investing (1); Online Retailing } \\
\text { (1); Online Services (1); Online Shopping (1); Online stock trading (1) }\end{array}$ \\
\hline Mobile (11) & $\begin{array}{l}\text { 3G Mobile Computing Device (1); Mobile (Cell) Phone Banking (1); } \\
\text { Mobile Broadband Wireless Access Technology-Based (MBWA) } \\
\text { games (1); Mobile Commerce (3); Mobile ICT Adoption (1); Mobile } \\
\text { Internet (1); Multi-purpose Information Appliances-Mobile Data } \\
\text { Services (1); Wireless Internet Service via Mobile Technology (WIMT) } \\
\text { (2); }\end{array}$ \\
\hline Website (16) & $\begin{array}{l}\text { Web-based Training (WBT) (1); Web Services (1); Websites (8); } \\
\text { Websites-Information Searching (1); Website-Women-centric (2); } \\
\text { Intermediary Website (1); Infomediaries Websites (1); Business } \\
\text { Homepage (1) }\end{array}$ \\
\hline
\end{tabular}

Table 11. Theories Used

\begin{tabular}{|l|c|c|c|c|c|c|c|c|c|}
\hline \multicolumn{1}{|c|}{ Theories } & TAM & TPB & TRA & DoI & Trust & SE & MM & PCUM & SCT \\
\hline Count & 88 & 17 & 8 & 49 & 7 & 8 & 2 & 3 & 2 \\
\hline Percent & 29.2 & 5.6 & 2.7 & 16.3 & 2.3 & 2.7 & .7 & 1 & .7 \\
\hline
\end{tabular}

was utilized in 17 studies, followed by TRA and SE, each contributing to eight studies. There were 47 other theories utilized in the 301 publications. In addition to these theories, 182 theoretical constructs were recorded from the various studies. ${ }^{5}$ The large number of theories and theoretical constructs employed clearly indicates the diversity of adoption and diffusion research in the IS research.

\section{SUMMARY AND CONCLUSIONS}

Our intention in this paper has been to provide an overview of the current state of adoption, acceptance, and diffusion research by presenting the results of a systematic and comprehensive review of 883 articles appearing across 337 different peer-reviewed journals during the period 1970-2007. We have presented the results of our investigation along a series of dimensions including the journals most often publishing articles on IS/IT adoption, acceptance, and diffusion, authors most active in the subject area (in terms of articles published), the most commonly used units of analysis, methodological practice and use of primary data, the theories and theoretical constructs utilized, and contexts and technologies examined. Our intention in conducting our investigation is to provide a

${ }^{5}$ Due to space limitations, the theoretical constructs are not listed here. The complete list is available from the authors. 
useful and usable resource for future researchers. In keeping with previous state of play studies of this nature, we posit that our findings highlight "promising lines of inquiry as well as the ones that are neglected and in need of renewed attention" (Palvia and Pinjani 2007, p. 10). Further, we argue that the findings of this study may help in directing limited and valuable research resources to fruitful lines of inquiry as well as strengthening the area of research by facilitating consideration of less used but useful alternative theoretical and methodological perspectives.

Although the three keywords, adoption, acceptance, and diffusion, are often used interchangeably by IS researchers, our results suggest that adoption is preferred over other two terms. It might be a point of further research to examine what determines the use of one of these three terms over the other. When considering research in terms of the research paradigm, the positivist approach is currently employed to a much greater extent than both the interpretive and descriptive/theoretical approaches. This suggests clear indication of adoption and diffusion researchers neglecting other paradigms, which has implications for editors, reviewers, and authors. Similarly, the utilization of empirical and quantitative techniques and survey research methods appears to have been much preferred over other available alternatives. It is clear that a rich diversity of theories and theoretical constructs exist within the extant literature, but researchers to date have overwhelmingly made use of just one theory, TAM, and its associated constructs "perceived usefulness" and "perceived ease of use." This suggests that IS/IT adoption and diffusion research is gradually moving toward overall homogeneity, which is clearly likely to weaken the field of technology adoption research. Therefore, we believe there are clear messages for authors to make greater use of the theoretical and methodological variety available to them, and for journal reviewers and editors to support the use of such alternative approaches, otherwise adoption and diffusion research itself will diffuse only within a limited domain. We anticipate this paper will prove to be a useful source of information for those readers who wish to learn more about the various facets pertaining to the existing body of published technology adoption and diffusion research in IS journals. Moreover, readers also may benefit by becoming aware of how the various research approaches and methods fit with the different theories, models, and units of analysis.

However, we fully acknowledge that our study has a number of limitations, and readers should be aware of these and indeed interpret the material presented in this paper within the context of these limitations. First, our search activities were restricted to occurrences of the three keywords in the article titles only, and we fully acknowledge that there may be numerous studies that lack all three keywords in the title, but still focus upon adoption and diffusion in the main text. For example, the works of Benbasat and Barki (2007), Choudrie and Dwivedi (2005a), and Lucas et al. (2007) focus on adoption and diffusion, but they did not appear in our search results as they lack all three keywords in the title. A further limitation is the extraction of theoretical and methodological data from limited search outputs. We limited our search to the journals indexed only in Web of Science ${ }^{\circledR}$, but there are many well-known journals in the IS field that are not indexed in this product, and this clearly will have limited our ability to identify all relevant articles, although further research is required to determine the extent of the influence of such factors. Although we believe that this paper has analyzed the largest number of articles in comparison to other existing review articles on this theme, we believe that comprehensive research is still required in order to reduce the impact of the limitations 
we have identified in order to provide a greater understanding of the domain of IS/IT adoption research.

\section{References $^{6}$}

Avison, D., Dwivedi, Y. K., Fitzgerald, G., and Powell, P. 2008. "The Beginnings of a New Era: Time to Reflect on 17 Years of the ISJ," Information Systems Journal (18:1), pp. 5-21.

Bagozzi, R. P. 2007. "The Legacy of the Technology Acceptance Model and a Proposal for a Paradigm Shift," Journal of the Association for Information Systems (8:4), pp. 244-254.

Benbasat, I., and Barki, H. 2007. "Quo vadis, TAM?," Journal of the Association for Information Systems (8:4), pp. 211-218

Brown, S. A., and Venkatesh, V. 2005. "Model of Adoption of Technology in Households: A Baseline Model Test and Extension Incorporating Household Life Cycle," MIS Quarterly (29:3), pp. 399-426. .

Choudrie J., and Dwivedi, Y. K. 2005a. "The Demographics of Broadband Residential Consumers of a British Local Community: The London Borough of Hillingdon," Journal of Computer Information Systems (45:4), pp. 93-101.

Choudrie, J., and Dwivedi, Y. K. 2005b. "Investigating the Research Approaches for Examining the Technology Adoption in the Household," Journal of Research Practice (1:1), pp. 1-12 (available at http://jrp.icaap.org/content/v1.1/choudrie.pdf).

Dwivedi Y. K., Choudrie J., and Brinkman, W. P. 2006. "Development of a Survey Instrument to Examine Consumer Adoption of Broadband," Industrial Management and Data Systems (106:5), pp. 700-718.

Dwivedi Y. K., Kiang, M., Williams, M. D., and Lal, B. 2008. "Profiling Research Published in the Journal of Electronic Commerce Research," Journal of Electronic Commerce Research (8:2), pp. 77-91.

Dwivedi, Y. K., Williams, M. D., Lal, B., and Schwarz, A. 2008. "Profiling Adoption, Acceptance, and Diffusion Research in the Information Systems Discipline," in Proceedings of the $16^{\text {th }}$ European Conference on Information Systems, W. Golden, T. Acton, K. Conboy, $\mathrm{H}$. van der Heijden, and V. Tuuainen, Galway, Ireland, June 9-11.

Dwivedi, Y. K., Williams, M. D., and Venkatesh, V. 2008. "Guest Editorial: A Profile of Adoption of Information \& Communication Technologies (ICT) Research in the Household Context," Information Systems Frontiers (http://dx.doi.org/10.1007/s10796-008-9101-8).

Galliers, R. D. 1992. "Choosing Information Systems Research Approaches," in Information Systems Research: Issues, Methods and Practical Guidelines, R. D. Galliers (ed.), Oxford, UK: Blackwell Scientific, pp. 144-162.

Galliers, R. D., and Land, F. F. 1987. "Choosing an Appropriate Information Systems Research Methodology," Communications of the ACM (30:11), pp. 900-902.

Hirschheim, R. 2007. "Introduction to the Special Issue on 'Quo Vadis TAM-Issues and Reflections on Technology Acceptance Research," Journal of the Association for Information Systems (8:4), pp. 203-205.

Jeyaraj, A., Rottman, J. W., and Lacity, M. C. 2006. "A Review of the Predictors, Linkages, and Biases in IT Innovation Adoption Research," Journal of Information Technology (21), pp. $1-23$.

King, W. R., and He, J. 2006. "A Meta-Analysis of the Technology Acceptance Model," Information \& Management (43), pp. 740-755.

${ }^{6}$ Due to space limitations, the articles analyzed for this review are not listed here, but the articles and other information relating to the development of this paper are available from the authors. 
Legris, P., Ingham, J., and Collerette, P. 2003. "Why Do People Use Information Technology? A Critical Review of the Technology Acceptance Model," Information \& Management (40), pp. 191-204.

Lucas, H. C., Swanson, E. B., and Zmud, R. W. 2007. "Implementation, Innovation, and Related Themes Over the Years in Information Systems Research," Journal of the Association for Information Systems (8:4), pp. 206-210.

Lyytinen, K., Baskerville, R., Iivari, J., and Te'eni, D. 2007. "Why the Old World Cannot Publish? Overcoming Challenges in Publishing High-Impact IS Research," European Journal of Information Systems (16:4), pp. 317-326.

Palvia, P., and Pinjani, P. 2007. "A Profile of Information Systems Research Published in Information \& Management," Information \& Management (44), pp. 1-11.

Schwarz, A., and Chin, W. 2007. "Looking Forward: Toward an Understanding of the Nature and Definition of IT Acceptance," Journal of the Association for Information Systems (8:4), pp. 230-243.

Silva, L. 2007. "Post-Positivist Review of Technology Acceptance Model," Journal of the Association for Information Systems (8:4), pp. 255-266.

Venkatesh, V. 2006. "Where to Go from Here? Thoughts on Future Directions for Research on Individual-Level Technology Adoption with a Focus on Decision Making," Decision Science (37), pp. 497-518.

Venkatesh, V., and Brown, S. A. 2001. "A Longitudinal Investigation of Personal Computers in Homes: Adoption Determinants and Emerging Challenges," MIS Quarterly (25:1), pp. 71-102.

Venkatesh, V., Davis, F. D., and Morris, M. G. 2007. "Dead or Alive? The Development, Trajectory and Future of Technology Adoption Research," Journal of the Association for Information Systems (8), pp. 267-286.

\section{About the Authors}

Yogesh K. Dwivedi is a lecturer in Information Systems at the School of Business and Economics, Swansea University, Wales, UK. He obtained his Ph.D. from the School of Information Systems, Computing and Mathematics, Brunel University. His doctoral research has been awarded the Highly Commended Award by the European Foundation for Management and Development and Emerald Group Publishing Ltd. His current research focuses on examining diffusion of IS research and also understanding the adoption and diffusion of ICT in organizations and society. As well as having presented at leading IS conferences such as European Conference on Informatoin Systems and the Americas' Conference on Information Systems, he has coauthored several papers which have appeared (or are forthcoming) in international referred journals such as Communications of the ACM, Information Systems Journal, Journal of Computer Information Systems, Industrial Management and Data Systems, and Information Systems Frontiers. He has authored a book, Consumer Adoption and Use of Broadband, and co-edited the Handbook of Research on Global Diffusion of Broadband Data Transmission. He is a member of the Association for Information Systems and Life Member of the Global Institute of Flexible Systems Management, New Delhi. He can be reached by at ykdwivedi@gmail.com.

Michael D. Williams is a professor in the School of Business and Economics at Swansea University. He holds a B.Sc. from the Council for National Academic Awards, an M.Ed. from the University of Cambridge, and a Ph.D. from the University of Sheffield. He has implemented and evaluated information systems in domains including finance, telecommunications, manufacturing, and government, is the author of numerous refereed and invited papers, and has obtained external research funding from sources including the European Union, the Nuffield Foundation, and the Welsh Assembly Government. He currently serves as an invited member of the Project Expert 
Group for a European Union funded project examining transformative use of ICT. He can be reached atm.d.williams@swansea.ac.uk.

Banita Lal is a lecturer in the Nottingham Business School, Nottingham Trent University, UK. She obtained her Ph.D. and M.Sc. in Information Systems from the School of Information Systems, Computing and Mathematics, Brunel University. Her research interests involve examining the individual and organizational adoption and usage of ICTs and technology-enabled alternative forms of working. She has published several research papers in internationally refereed journals such as Industrial Management and Data Systems, Information Systems Frontiers, Electronic Government, International Journal of Mobile Communications, and Transforming Government: People, Process and Policy, and has presented several papers at several international conferences. She can be reached at banita.la.@ntu.ac.uk. 